\title{
The evolutionary significance of dry and wet season forms in some tropical butterflies
}

\author{
PAUL M. BRAKEFIELD
}

Department of Biological Sciences, University of Exeter, Washington Singer Laboratories, Perry Road, Exeter EX4 4QG

\section{AND}

\section{TORBEN B. LARSEN}

clo Danida, Royal Danish Embassy, 2 Golf Links, New Delhi 110 003, India

An explanation is developed for the adaptive significance of the forms characteristic of the dry season and wet season adult generations of some tropical butterflies. The divergent phenotypes are accounted for as adaptive responses to a shift in the optimum balance between dependence on the alternative (but interdependent) strategies of active anti-predator devices and of crypsis. The seasonal polyphenisms exhibited by the satyrines Melanitis leda (Fabricius) and Orsotrioena medus (Fabricius) and the nymphalid Junonia almana (Linné) are examined in detail. The wet season forms show prominent marginal eyespot patterns which are displayed at rest and function principally in the deflection of attacks by vertebrate predators. In contrast, the dry season forms show very small or no spots and are wholly cryptic. Wet season butterflies are more active in general than those in the dry season when aestivation behaviour is often observed. The alternative phenotypes represent responses to the differences in behaviour, environment and nature of predation. Reproductive success is optimized in each season by an interaction of phenotype and behaviour. The hypothesis must be tested in detail by an investigation of the behavioural ecology and population biology of particular species. It is argued that these seasonal polyphenisms provide examples of adaptations to a repeating pattern of changing environments where the mode of selection is, in broad terms, understood.

KEY WORDS:-Polyphenism - butterfly - dry season - wet season - eyespots - deflection crypsis - predators - visual selection - adaptation.

\section{CONTENTS}

Introduction

The basic hypothesis

Examples of polyphenic species.

Melanitis leda

Orsotrioena medus

Junonia almana.

Discussion .

Acknowledgements

References. 


\section{INTRODUCTION}

Shapiro (1976) defines seasonal polyphenism as an annually repeating pattern of changing phenotypic ratios in successive generations under some kind of environmental control. He reviews the extensive literature on the occurrence of this phenomenon in invertebrates with particular reference to butterflies. Although seasonal polyphenism in butterflies has been investigated for over a century, little understanding has been gained of its adaptive value. It is only in those species of Pieridae which show increased melanin deposition in cool season adults that this has been achieved (Watt, 1969; Shapiro, 1976). In the most rigorous experiments, Douglas \& Grula (1978) working with Nathalis iole (Boisduval), demonstrated that the higher density of melanic scales increases the efficiency of absorption of thermal energy. Presumably this facilitates a higher intensity and longer duration of activity (see Roland, 1982). The sometimes striking examples of seasonal polyphenisms in tropical Satyrinae have rarely been studied (see Owen, 1971). In this paper we describe some of these satyrine species in detail together 'with several examples in other groups of tropical butterflies. We develop an explanation for the adaptive significance of the forms characteristic of the dry season and wet season generations. These species are of particular evolutionary interest since selection by visually-orientated predators is implicated in contrast to the examples of thermal melanism in the Pieridae.

Much of the work on seasonal polyphenisms in butterflies has been concerned with the control of the phenotypic changes. Studies on species of Pieridae, Nymphalidae, Lycaenidae and Hesperiidae have generally found that photoperiod acting during some part of the larval period is the predominant environmental factor regulating phenotype (e.g. Sakai \& Masaki 1965; Shapiro, 1976, 1980; Ishii \& Hidaka 1979). However, in some cases temperature interacts with photoperiod. In stocks of Precis octavia Cramer (Nymphalidae) from Kenya temperature is apparently the sole environmental factor involved in determining the seasonal forms (McLeod, 1968). In areas near the equator photoperiod fails as a seaonal indicator. It seems that in species of Satyrinae the controlling factor(s) has not been established although Owen (1971) reports that he produced the dry season form of Melanitis leda (Fabricius) in the wet season by rearing larvae at a low $(60 \%)$ relative humidity. In the present study the precise nature of the proximate environmental control is not relevant since we are concerned with how selection favours the divergent phenotypes found in each season. As Shapiro (1976) has emphasized, the ability to undergo specific directional phenotypic modification has a genetic basis and should itself be subject to selection.

The seasonal polyphenism in the species we examine often extends to characters other than wing pattern. We recognize the involvement of the following.

(1) Wing pattern:

(a) degree of development of the underside submarginal eyespots;

(b) overall degree of crypsis;

(c) upperside pattern.

(2) Wing shape and size.

(3) Adult behaviour:

(a) level and nature of activity;

(b) choice of resting site. 


\section{THE BASIC HYPOTHESIS}

One of us has developed a model to account for the variation in the spot pattern of the Palaearctic satyrine Maniola jurtina (Linné) in terms of visual selection (Brakefield, 1984). Aspects of this model, particularly those relating to the marked sexual dimorphism, are of wider application (cf. Young, 1980). Various types of evidence, including beak-damage patterns and results from experiments using marked insects and captive birds, show that small eyespot markings on the wing margins can deflect the attacks of vertebrate predators away from the vulnerable body. Large well-differentiated eyespots, which may be associated with a form of flash colouration, can startle or confuse a predator and so evoke a withdrawal response (see discussions by Blest, 1957; Edmunds, 1974; Brakefield, 1984 and also Robbins, 1980). The evolution of spot patterns as active anti-predator mechanisms must have been closely integrated with that of cryptic coloration of the wing pattern (see Schwanwitsch, 1948; Nijhout, 1978, 1980). Numerous experimental studies have demonstrated the adaptive value of crypsis. It involves a matching of pattern and background which must extend to features of grain, geometry, contrast and colour (Endler, 1978). The conspicuousness of an organism's colour pattern also depends on prey behaviour, predator vision and hunting tactics.

The model for $M$. jurtina proposes that the spot pattern of a butterfly reflects the optimum balance between its effectiveness in enabling the butterfly to escape a predator's attack and to remain undetected by a searching predator. This balance depends on the butterfly's activity pattern and habitat selection since these factors influence the likelihood of encounter by (different) predators and the degree of matching between colour pattern and background. Ecological studies on $M$. jurtina have shown that males are in general more active than females (Brakefield, 1982). Whilst females emphasize a single large and contrasted forewing eyespot, males show a more even spot distribution over the wings. The model described in detail by Brakefield (1984) proposes that since females are more likely to be encountered by a predator whilst resting inactively, their relative lack of hindwing spots increases the effectiveness of crypsis (in uniform grassland). The forewing eyespot is usually hidden at rest but on disturbance may be exposed to evoke a withdrawal response. Males, which because of their higher level of activity are more conspicuous to predators, show a more even spotting which functions as a general deflection device. In some circumstances a large and prominent eyespot is likely to increase the probability of attracting a predator. Independent evidence for some components of the model has been obtained by Bengtson (1981) and Brakefield (1984).

We will show that the phenotypes characteristic of the seasonal forms of some tropical butterflies can be accounted for as adaptive responses to shifts in the optimum balance between dependence on the alternative (but interdependent) strategies of active anti-predator devices and of crypsis.

\section{EXAMPLES OF POLYPHENIC SPECIES}

Most Satyrinae in the Old World tropics are medium-sized butterflies with moderate powers of flight. Their larval food plants are grasses, bamboos and occasionally palms. Many species have prominent submarginal eyespots on the 
underside of the wings. These eyespots have the characteristics of typical deflective markings. They are most evident at close to medium distances when the butterfly is at rest with its wings closed above the body. Other Satyrinae have more typical cryptic patterns in which the expression of the presumptive ancestral ring of eyespots (see Schwanwitsch, 1948; Nijhout, 1978) is suppressed. Henotesia iboina Ward (Fig. 1) shows an interesting example where only the part of an eyespot visible at rest is suppressed. In parts of the tropics where marked dry and wet seasons occur, many species of Satyrinae and some in other groups have distinct seasonal forms. A number of such species are listed in Table 1. The dry season form is invariably more cryptic than the wet season form which, in the satyrine examples, shows strongly developed deflective patterns of eyespots. Intermediate phenotypes between the forms are found in all the species. However, they do not normally occur at a high frequency. In the wetter tropics, species with seasonal forms elsewhere are monomorphic with the wet season phenotype (the dry season form occurring as rarities). However, Kirk (1982) has shown that in three species of Mycalesis from the Malayan peninsula and Thailand that butterflies from an area where only the wet season form is found tend to exhibit larger spots than wet season adults from an area where polyphenism occurs in response to climatic changes.

We have selected three species included in Table 1 for closer examination. They are Melanitis leda (Fabricius), Orsotrioena medus (Fabricius) and Junonia almana (Linné). This last species is discussed because it provides a striking example of the parallel evolution of an adaptation to seasonal environments in two taxonomically well-removed groups representing the Satyrinae and Nymphalinae, respectively. The other Satyrinae in Table 1 conform to the same basic principles described below.

\section{Melanitis leda}

This butterfly is common in the Australian, Oriental and Afrotropical regions. In part of the rainforest zone of Asia and Africa the species is effectively

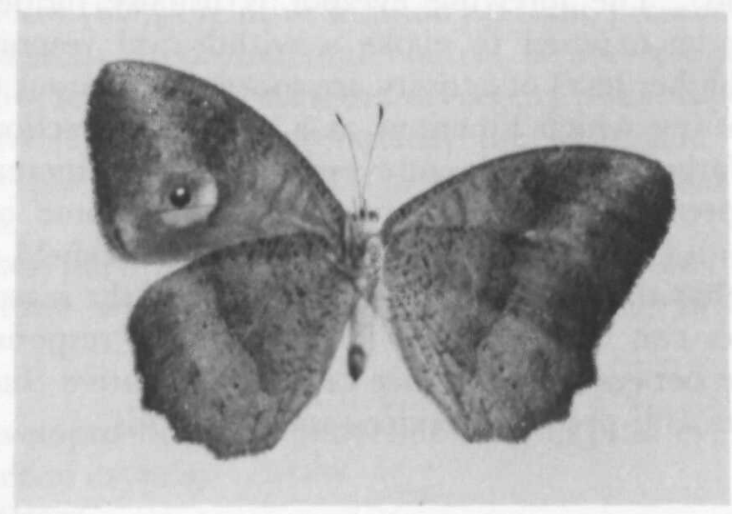

Figure 1. Henotesia iboina (underside). A monomorphic species with a cryptic pattern. The genus Henotesia also includes species which are monomorphic in the non-cryptic form, and species with seasonal polyphenism. The major eyespot on the underside of the forewing is secondarily reduced in the area where it would have been exposed when at rest, suggesting that it evolved from an originally non-cryptic form. 
Table 1. Examples of Afrotropical, Oriental and Australian butterflies with a cryptic dry season form and a less cryptic wet season form (the list is not intended to be exhaustive and no more than three examples are given for any one genus)

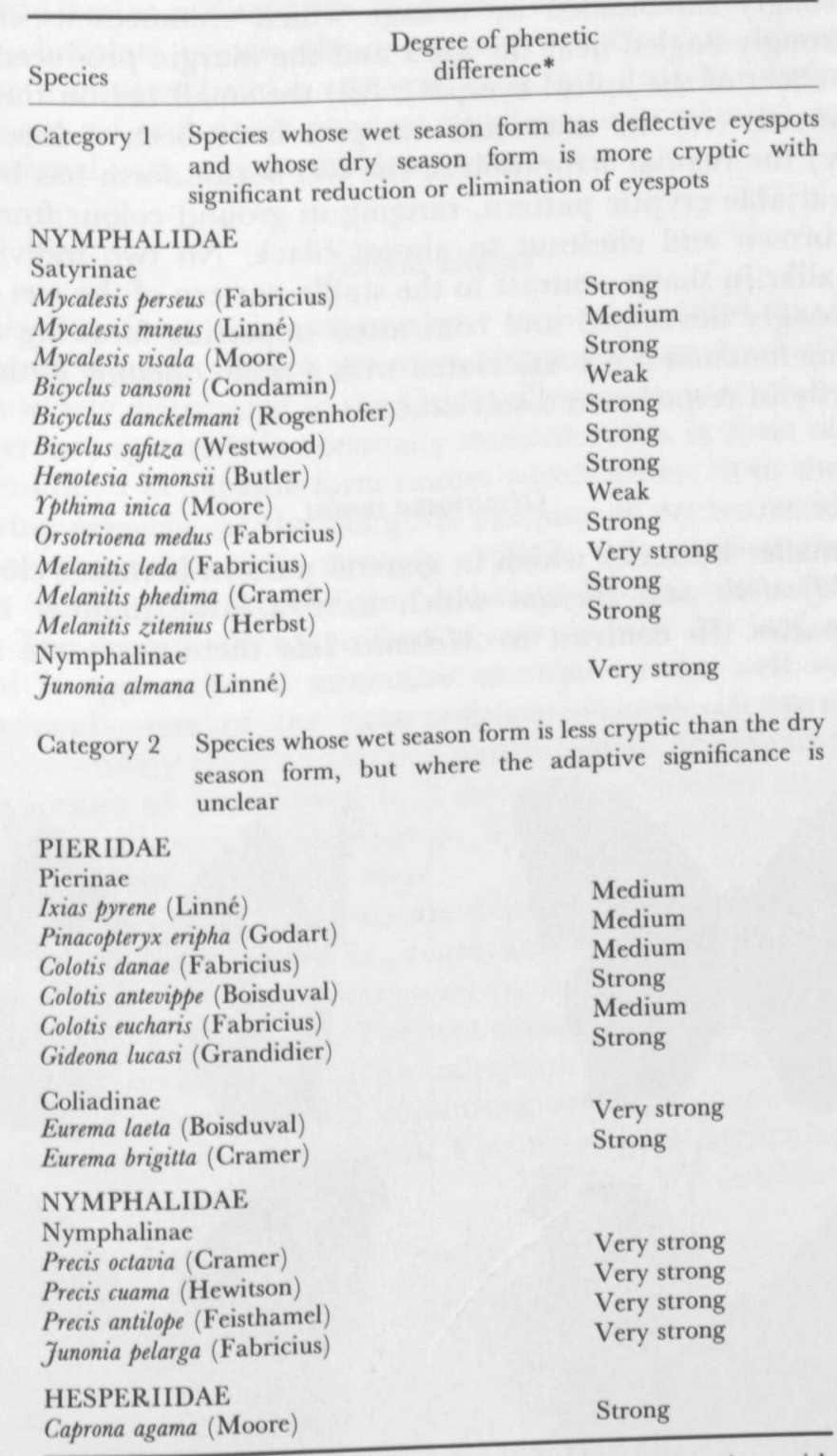

*Very strong $=$ drastic pattern alteration in conjunction with changes in wing shape and/or behaviour and/or upperside pattern; Strong $=$ drastic changes in pattern to achieve crypsis without strong changes in wing shape or upperside pattern; Medium = clear tendency towards dry season crypsis; Weak = chiefly reduction in size of eyespots with few other changes. 
monomorphic in the wet season form. This form (Fig. 2) has pointed forewings, the uppersides with relatively small apical eyespots. The underside is brown with fine light irroration and all wings have prominent marginal eyespots. There is little individual variation except some in spot size. The dry season form, which occurs as far apart as Australia, India, Arabia and Africa differs in the following respects: (i) the eyespot of the forewing upperside is more prominent and more strongly surrounded by orange which enhances its effect; (ii) the forewing is strongly angled near the apex and the margin produced (which also increases the effect of the apical eyespot); (iii) the small tail on the hindwing is more pronounced; (iv) the underside eyespots have been reduced to minute white dots; (v) the regular irroration of the wet season form has been replaced by a highly variable cryptic pattern, ranging in ground colour from a light tan over darker brown and chestnut to almost black. No two individuals (quite literally) are alike in sharp contrast to the stable pattern of the wet season form. The more strongly developed and contrasted upperside forewing eyespot may have a startling function if it is associated with a rapid opening of the wings by a resting butterfly in response to disturbance.

\section{Orsotrioena medus}

This is a smaller butterfly which in general pattern is rather close to that of the genera Mycalesis and Bicyclus which have a large number of seasonally polyphenic species. In contrast to Melanitis leda there are some recognizable

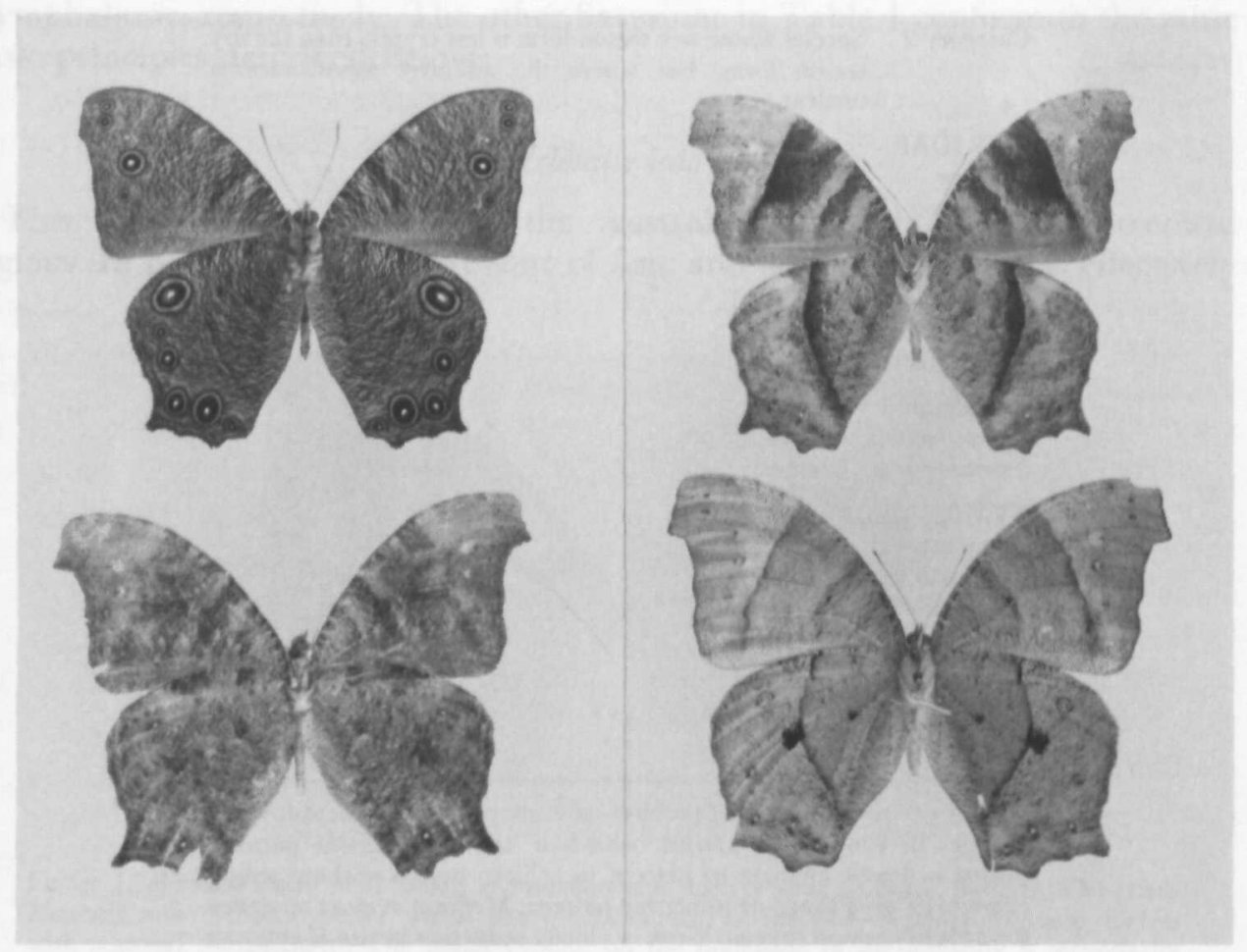

Figure 2. Melanitis leda. The top left specimen shows the underside of the wet season form. The other specimens illustrate variation in the underside of the dry season form. 
subspecies along its range which extends from Sri Lanka via India and southeastern Asia to New Guinea and Australia. In most of this distribution it is monomorphic, but in India, Bangladesh and parts of Thailand and Burma it has a dry season form. The underside of the wet season form (Fig. 3) is nearly black with prominent marginal eyespots and a white discal band running more or less straight from the anal angle of the hindwings to the apex of the forewings. This band may act as a disruptive marking. The underside of the dry season form is deep chocolate brown, the eyespots are reduced to minute white dots and the white transverse band is replaced by a thin dark line fusing two brown areas. There are no noticeable changes in wing shape, though some Mycalesis have more pointed wing tips in the dry season form.

\section{Junonia almana}

This species is a deep, rich orange above with some black patterning and a series of 'peacock' eyespots which are more elaborate than those of the Satyrinae (Fig. 4). It is widely distributed in the Oriental region in a number of subspecies. Like the other two species it is essentially monomorphic in most of its range. In the driest localities a dry season form occurs which differs from the typical form in the following respects: (i) the marginal eyespots of the underside are absent; (ii) the colour pattern is more strongly cryptic; (iii) the forewings are much more falcate; (iv) the anal angle of the hindwings is produced to form a tapering tail (Fig. 4). The overall effect is to form a very realistic dry leaf, complete with stalk. Indeed it approaches a miniature example of the well known Kallima inachus (Boisduval), one of the most celebrated cases of camouflage. It is remarkable how closely these alterations parallel those of Melanitis leda (Fig. 2). The African species of Precis listed in Table 1 show similar alterations to the wing shape in the dry season form but do not have well-differentiated eyespots on the underside of the wet season form.

The strong, parallel phenotypic variation and its association with dry and wet season climatic regimes in many Satyrinae and some other butterflies is clear. One would expect this to be accompanied by differences in behaviour, though actual evidence for this is weaker. The wet season forms usually fly at a time of optimal breeding conditions with an adequate food plant supply. The dry season forms occur when breeding conditions are poor or even absent due to complete desiccation of the food plants. This may be of particular relevance to
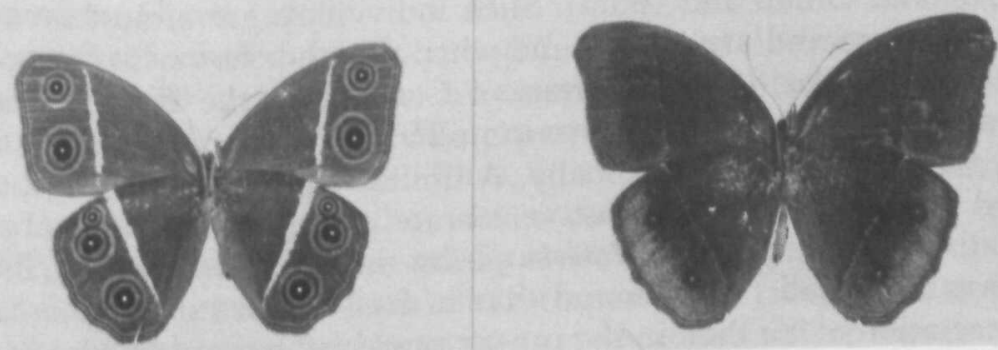

Figure 3. Orsotrioena medus. The specimen on the left is the less cryptic wet season form and that on the right is the dry season form (undersides). Both were collected in Sikkim. 


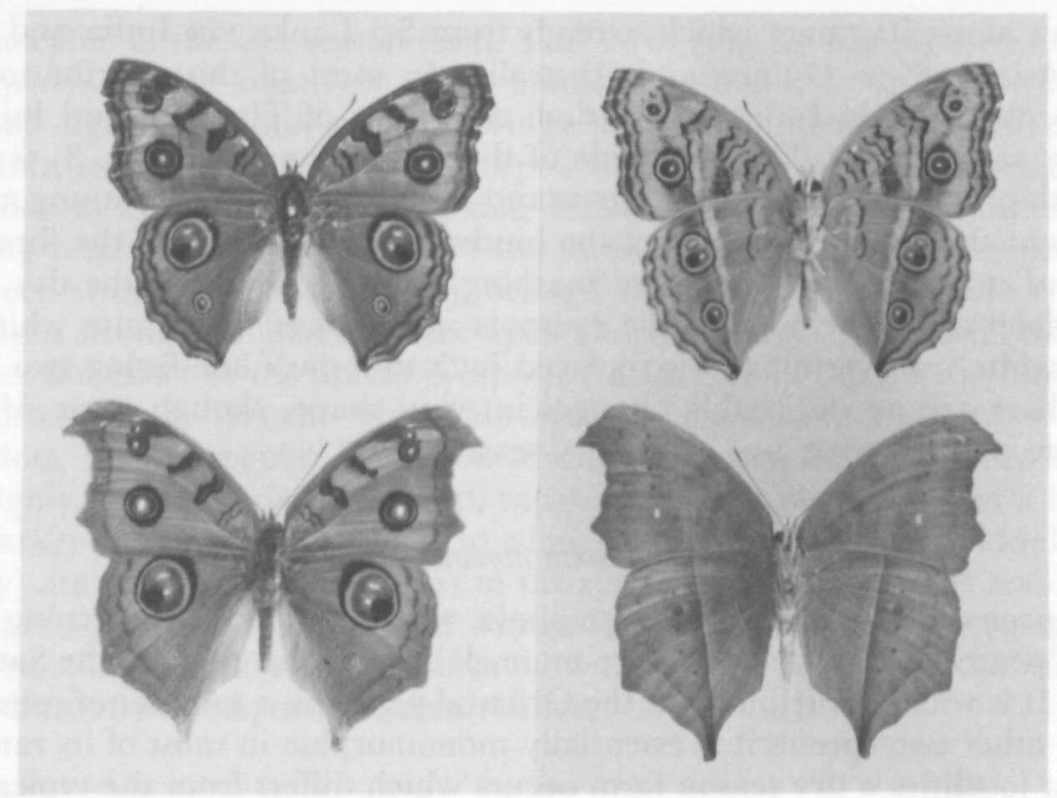

Figure 4. Junonia almana. The top row illustrates the upperside (left) and underside (right) of the wet season form from India. The bottom row illustrates the respective wing surfaces of the dry season form.

the Satyrinae which are grass-feeding, since grasses are often among the first plants to dry out. Thus adult butterflies during the dry season must generally spend long periods in a state of semiquiescence or aestivation prior to the onset of rains.

It is well known that Precis octavia and some other polyphenic members of the genus spend the dry season in small aggregations with little or no activity. The places selected for aestivation are often quarries, well holes and disused sheds (Trimen, 1887; Swanepoel, 1953; Owen, 1971; L. McLeod, pers. comm.). L. McLeod also found that in the dry season specimens of Melanitis leda settled on the trunks of trees and inside holes in the trunks. They were generally rather inactive except on particularly cool days (some species, including $M$. leda and funonia almana, may show seasonal changes in their resting posture, e.g. Wynther-Blyth, 1957). Larsen (unpub. data) has often disturbed worn individuals of Colotis, Bicyclus, Mycalesis and M. leda during the dry season in areas where the vegetation was completely desiccated (especially Sudan, northern Nigeria, Oman and India). Such individuals are almost invariably of the dry season form and are often found when no other butterflies are observed. In the dry season Pacific coast forests of Costa Rica the Pierid Eurema daira (Godart) aestivates in inactive groups in understory scrub (Brakefield, 1979). If disturbed, the butterflies fly erratically. A similar aggregating behaviour which may afford some protection against vertebrate predators has been observed in an aestivating population of Maniola jurtina in northern Spain (Brakefield, 1979). Masetti \& Scali (1972) found that in Italy aestivating $M$. jurtina had a longer expectation of life than in the pre- or post-aestivation periods. Aestivating females of $M$. jurtina and of another Satyrine, Heteronympha merope (Fabricius), in Australia show a delayed ovarian development (Scali, 1971; Edwards, 1973). In 
Oman, Hipparchia parisatis (Kollar) eclose in April or May and re-emerge from semi-quiescence in September and October to oviposit at the onset of the winter rains (Larsen \& Larsen, 1980; Larsen, 1983). In Lebanon the Pierid Gonepteryx rhamni (Linné) enters a state of semi-quiescence immediately on emerging, reappearing in autumn. It then migrates down to mid-altitudes to hibernate before returning to the high mountains to oviposit in early spring (Larsen, 1974). Thus, although direct evidence is limited, there are good grounds for assuming that dry season adults of the species discussed will have a longer life expectancy and be more motionless than the corresponding wet season butterflies. In the case of Melanitis leda an additional argument may be raised. It is a crepuscular insect, but it can be active most of the day in rainforest habitat and on overcast days during the wet season.

\section{DISCUSSION}

The preceding sections demonstrate that there are characteristic phenotypic differences between the wet and dry season forms of many tropical Satyrinae in both Asia and Africa. In one case this is very closely paralleled by a member of the Nymphalinae. We have also shown that there are differences in behaviour, probably more far-reaching than we can show at present. Clearly the phenomenon of seasonal polyphenism, which has a genetic basis, has evolved independently on many occasions. It must have strong adaptive value.

The phenotypic differences between the seasonal forms when considered in relation to the basic model imply that selection for crypsis is very strong in the dry season and weaker in the wet season when selection favours patterns which can function as active anti-predator devices. This disruptive pattern of visual selection is associated with a marked seasonal difference in the availability of adult and larval resources. We suggest that reproductive success during the wet season is optimized by an active adult life with a relatively rapid mating and subsequent oviposition on the adequate or abundant supply of food plants. In the dry season, courtship and oviposition behaviour may be absent or only occur at a low level. A high activity will not be favoured and survival rate will be maximized by quiescence or aestivation behaviour. Selection on the wing pattern and behaviour in each season will also be influenced by the type of predation. The most likely predators during the dry season are browsers including geckos and skinks as well as certain birds and small mammals; in the wet season active visual predators such as jays, shrikes and agamids are probably more important. Some elements of these conclusions were partially anticipated by Owen (1980).

The species included in Category 2 in Table 1 resemble the examples described in detail in most respects, except that their wet season forms do not have obvious deflective marks. We expect that an extension of the hypothesis developed here is still relevant. Thus, in the Colotis group (epitomized by $C$. antevippe in Africa, Fig. 5) the wet season adults often have pure white undersides, while the dry season form is clearly more cryptic. The white coloration of the wet season form may be aposematic (see Marsh \& Rothschild, 1974). The polyphenism in this group may therefore reflect selection favouring crypsis in relatively inactive dry season butterflies and warning coloration in more active wet season adults. The more prominent upperside black markings of 


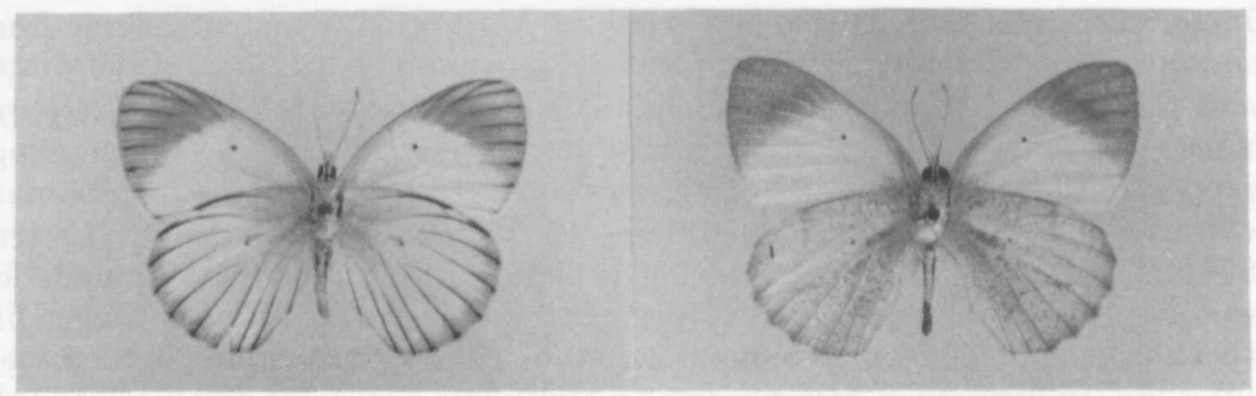

Figure 5. Colotis antevippe (undersides). The left specimen illustrates the wet season form, the specimen on the right, the cryptic dry season form.

most wet season Colotis may have a thermoregulatory function. Some of the members of the genus Eurema (especially $E$. laeta in India) additionally show changes in wing shape in the dry season which probably enhance crypsis. The adaptive value of their polyphenism is likely to be similar to that found in the Colotis group. In pure visual terms the most dramatic example of seasonal polyphenism is Precis octavia from Africa (McLeod, 1968; Owen, 1971, 1980). Both the upper- and undersides of the dry season form are radically transformed. Owen notes differences in behaviour between the forms. These probably differ in their degree of crypsis. Aposematism may also be involved. Disruptive patterns of selection involving crypsis may also be a factor in the seasonal polyphenisms exhibited by the nymphalids, Araschnia levana and species of Polygonia (see Shapiro, 1976).

In Melanitis leda and probably in at least some other species a more variable phenotype is characteristic of dry season butterflies (Owen, 1971; our study). This observation merits further investigation in relation to Endler's (1978) prediction that pattern diversity amongst forms subject to predation on the same background should decrease with increased visual selection intensity. It may also be argued that greater variability in dry season adults would enhance crypsis and decrease the likelihood of search image formation by vertebrate predators.

A more detailed investigation of the behavioural ecology and population biology of a number of the satyrine species is necessary to rigorously test our model. For example, the effectiveness of the prominent spot pattern of a wet season form(s) could be investigated by a detailed analysis of wing damage (cf. Bowers \& Wiernasz, 1979; also see Young 1980; Larsen, 1982). The rates at which the phenotypes characteristic of each season sustain wing damage from different types of predator attacks can be compared by using mark-release-recapture techniques (see Brakefield, 1984). Nevertheless, our preliminary observations provide strong evidence for the adaptive value of the dry and wet season forms. These differ in degree of crypsis with vertebrate predators acting as selective agencies. Shapiro (1976) has emphasized the value of work on seasonal polyphenisms for developing evolutionary theory. We believe that further study will confirm the basis of our reasoning and thus provide examples of adaptations to a repeating pattern of changing environments where the mode of selection is, in broad terms, understood. Phenotypic plasticity supplies the mechanism by which these butterfly species can maximize their 
fitness in successive generations experiencing divergent ecological conditions. An analysis involving crosses between different stocks of species which show gesgraphical variation in the expression of the polyphenism may provide information about the evolution of the underlying genetic basis of the adaptation.

\section{ACKNOWLEDGEMENTS}

The first author would like to thank Professor W. Scharloo and the Department of Population and Evolutionary Biology at the University of Utrecht for facilities provided during the preparation of this paper. We are grateful to Professor A. J. Cain, Mr L. McLeod, Professor D. F. Owen and Professor A. M. Shapiro for their comments.

\section{REFERENCES}

BENGTSON, S. A., 1981. Does bird predation influence the spot-number variation in Maniola jurtina (Lepidoptera)? Biological Journal of the Linnean Society, 15: 23-27.

BLEST, A. D., 1957. The function of eyespot patterns in the Lepidoptera. Behaviour, 11: 209-256.

BLOWERS, M. D. \& WIERNASZ, D. C., 1979. Avian predation on the palatable butterfly, Cercyonis pegala (Satyridae). Ecological Entomology, 4: 205-209.

BRAKEFIELD, P. M., 1979. An experimental study of the maintenance of variation in spot pattern in Maniola jurtina. Unpublished Ph.D. Thesis, University of Liverpool.

BRAKEFIELD, P. M., 1982. Ecological studies on the butterfly Maniola jurtina in Britain. I. Adult behaviour, microdistribution and dispersal. Journal of Animal Ecology, 51: 713-726.

BRAKEFIELD, P. M., 1984. The ecological genetics of quantitative characters in Maniola jurtina and other butterflies. Symposia of the Royal Entomological Society, 11, The Biology of Butterflies, 167-190.

DOUGLAS, M. M. \& GRULA, J. W., 1978. Thermoregulatory adaptations allowing ecological range expansion by the pierid butterfly Nathalis iole Boisduval. Evolution, 32: 776-783.

EDMUNDS, M., 1974, Defense in Animals. London: Longman.

EDWARDS, E. D., 1973. Delayed ovarian development and aestivation in adult females of Heteronympha merope merope (Lepidoptera: Satyrinae). Journal of the Australian Entomological Society, 12: 92-98.

ENDLER, J. A., 1978. A predator's view of animal color patterns. Evolutionary Biology, 11: 319-364.

ISHII, M. \& HIDAKA, T., 1979. Seasonal polymorphism of the adult rice-plant skipper, Parnara guttata guttata (Lepidoptera: Hesperiidae) and its control. Applied Entomology and Zoology, 14: 173-184.

KIRK, W. D. J., 1982. Variation of forewing spot number in the mineus-group of Mycalesis (HBN.) (Lepidoptera, Satyridae) in S.E. Asia. The Malayan Nature Fournal, 35: 229-236.

LARSEN, T. B., 1974. Butterfies of Lebanon. Beirut: National Council for Scientific Research.

LARSEN, T. B., 1982. Heavy predation by birds or lizards of Hipparchia parisatis (Kollar) (Lepidoptera: Satyridae) in Oman. Entomologist's Gazette, 33: 5-7.

LARSEN, T. B., 1984. The Butterflies of the Arabian Peninsula. London: Stacey International.

LARSEN, T. B. \& LARSEN, K., 1980. Butterflies of Oman. Edinburgh: Bartholomew Books.

McLEOD, L. 1968. Controlled environment experiments with Precis octavia Cram. (Nymphalidae). Journal of Research on the Lepidoptera, 7: 1-18.

MARSH, W. \& ROTHSCHILD, M., 1974. Aposematic and cryptic Lepidoptera tested on the Mouse. Journal of Zoology, London, 174: 89-122.

MASETTI, M. \& SCALI, V., 1972. Ecological adjustments of the reproductive biology in Maniola jurtina from Tuscany. Accademia Nazionale Dei Lincei, 53: 460-468.

NIJHOUT, H. F., 1978. Wing pattern formation in the Lepidoptera: A model. The Journal of Experimental

Zoology, 206: 119-136.
NIJHOUT, H. F., 1980. Pattern formation on Lepidoptera wings: Determination of an eyespot. Developmental Biology, 80: 267-274.

OWEN, D. F., 1971. Tropical Butterflies. Oxford: Clarendon Press.

OWEN, D. F., 1980. Camouflage and mimicry. Oxford: Oxford University Press.

ROBBINS, R. K., 1980. the Lycaenid "false head" hypothesis: Historical review and quantitative analysis. Journal of the Lepidopterists' Society, 34: 194-208.

ROLAND, J., 1982. Melanism and diel activity of alpine Colias (Lepidoptera: Pieridae). Oecologia, 53: 214-221.

SAKAI, T. \& MASAKI, S., 1965. Photoperiod as a factor causing seasonal forms in Lycaena phlaeas daimio Seitz. Kontyu (Tokyo), 33: 275-283. 
SCALI, V., 1971. Imaginal diapause and gonadal maturation of Maniola jurtina (Lepidoptera: Satyridae) from Tuscany. Journal of Animal Ecology, 40: 435-440.

SCHWANWITSCH, B., 1948. Evolution of the wing-pattern in palaearctic Satyridae. IV. Polymorphic radiation and parallelism. Acta Zoologica, 29: 1-61.

SHAPIRO, A. M., 1976. Seasonal polyphenism. Evolutionary Biology, 9: 259-333.

SHAPIRO, A. M., 1980. Convergence in pierine polyphenisms (Lepidoptera). Journal of Natural History, 14: 781-802.

SWANEPOEL, D. A., 1953. Butterflies of South Africa. Cape Town: Maskew Miller.

TRIMEN, R., 1887. South African Butterflies; Nymphalinae. London; Trübner and Co.

WATT, W. B., 1969. Adaptive significance of pigment polymorphisms in Colias butterflies. II. Thermoregulation and photoperiodically controlled melanin variation in Colias eurytheme. Proceedings of the National Academy of Sciences, U.S., 63: 767-774.

WYNTHER-BLYTH, M. A., 1957. Butterflies of the Indian Region. Bombay: Bombay Natural History Society.

YOUNG, A. M., 1980. The interaction of predators and "eyespot butterflies" feeding on rotting fruits and soupy fungi in tropical forests: Variations on a theme developed by the Muyshondts and Arthur M. Shapiro. The Entomologist's Record, 90: 63-69. 